\title{
CONSIDERAÇÕES SOBRE O TRANSPORTE DE SEDIMENTOS NA PLATAFORMA CONTINENTAL NAS PROXIMIDADES DAS ILHAS MARICÁS, RJ
}

\author{
DIETER MUEHE* e ELZA CORREIA SUCHAROV**
}

\begin{abstract}
A preliminary survey of bottom sediment transport within the inner continental shelf in the vicinity of Maricás islands, Rio de Janeiro, was carried out through shortterm current and wave measurements.

Results indicate that transport is generally extremely small under good weather conditions. Based on finer sediment size eastward of Maricás islands it is suggested that transport occurs from west to east under storm condition when wind blows from SW and wave activity is high
\end{abstract}

INTRODUÇÃo A região costeira entre a Baía da Guanabara e o Cabo Frio é caracterizada por extensos cordð̃es litorâneos que, impedindo o aporte de sedimentos fluviais para a plataforma continental, fazem com que os mesmos sejam retidos no sistema de lagunas que se desenvolvem à retaguarda desses cordðes. Os promontórios rochosos, que por sua vez separam os diferentes arcos praiais, são formados por rochas coesas (gnaisse e granito) do complexo cristalino, cuja resistência ao ataque das ondas é suficientemente forte para não constituir significativos fornecedores de sedimentos. Desta forma, os sedimentos relictos da plataforma continental interna passam a constituir a principal fonte de sedimentos para a manutenção do conjunto de praias que, ao lado dos atrativos para o lazer, representam a melhor proteção contra a ação erosiva das ondas.

Considerando a atual tendência de subida do nivel do mar da ordem de 10 a $15 \mathrm{~mm} / \mathrm{século}$, esta fonte, tanto por esgotamento quanto pela progressiva diminuição das áreas afetadas pela ação das ondas, pode deixar de suprir a quantidade de sedimentos necessários à manutenção das praias, provocando fenômenos erosivos nas mesmas.
Observaçøes recentes em diferentes regiðes costeiras vêm confirmando essa tendência em nivel mundial (Zenkovich, 1976).

No Brasil, de maneira geral, praticamente inexistem observaçð̃es a longo prazo sobre o comportamento das praias, se bem que efeitos erosivos são nitidamente visiveis em amplas extensðes do litoral do nordeste. No caso específico da área de estudo do presente trabalho, não aparecem efeitos erosivos notáveis; entretanto, o padrão de distribuição dos sedimentos na antepraia (shoreface) de Itaipu, Guaratiba e Jaconé, caracterizado por uma diminuição da dimensão granulométrica a partir da zona de rompentes em direção ao mar aberto, até profundidades da ordem de $9 \mathrm{~m}$, e posterior aumento da granulometria em direção a profundidades maiores (Muehe, 1979), é típico de praias sob efeitos erosivos conforme modelo apresentado por Swift (1976). Essa tendência erosiva pode ser perigosamente acelerada por dragagem de areia na praia ou na plataforma continental e por obras de engenharia que possam interromper o fluxo de sedimentos.

Desta forma, é imprescindível a realização de estudos

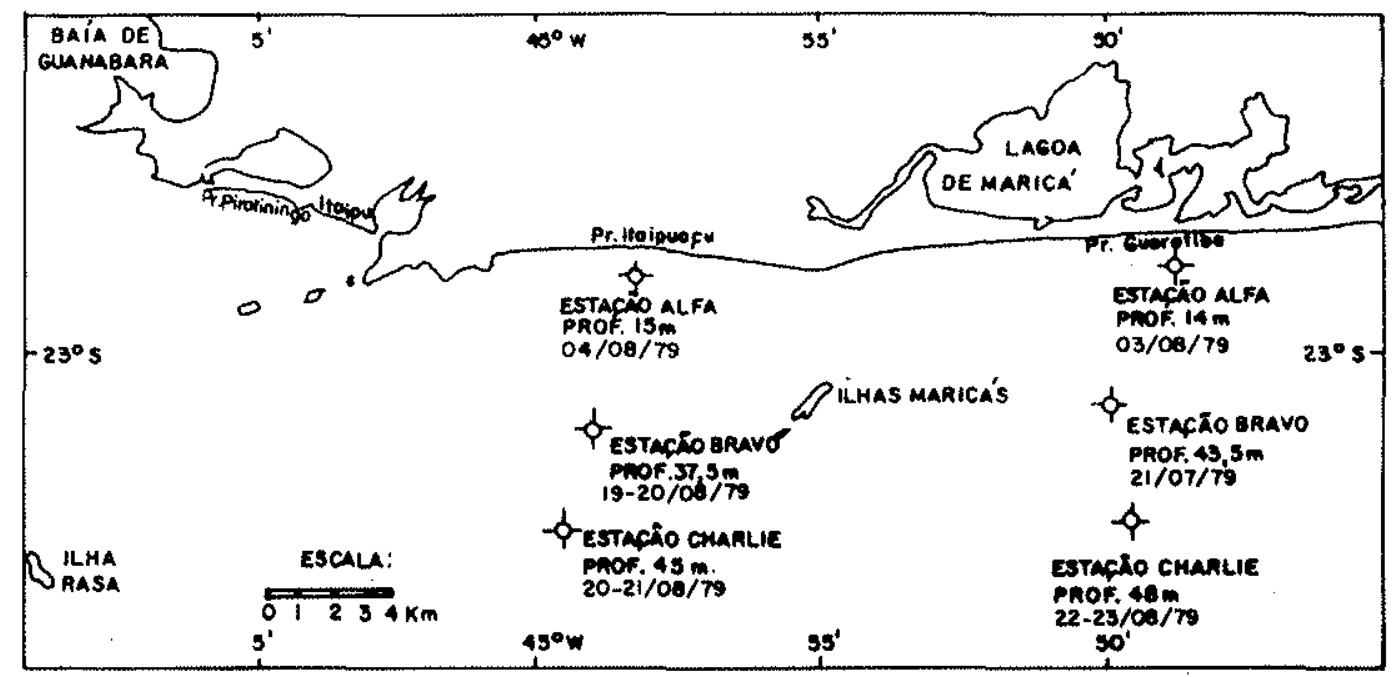

Figura l - Localizaçdo das estaçðes oceanograficas

* Departamento de Geografia do Instituto de Geociências, UFRJ, CEP 21941, Rio de Janeiro, RJ - Pesquisador do CNPq.

** Departamento de Meteorologia do Instituto de Geociências, UFRJ, CEP 21941, Rio de Janeiro, RJ 
que permitam avaliar a direção e a quantidade de sedimentos mobilizados na plataforma continental, por ação conjugada de ondas e correntes, antes de efetuar-se qualquer tipo de interferência no sistema costeiro.

$O$ objetivo do presente trabalho é analisar, numa primeira aproximação, a ação das ondas e correntes sobre o fundo marinho, da plataforma continental interna nas proximidades das ilhas Maricás (Fig. 1), com vistas à erosão e ao transporte dos sedimentos.

A coleta de dados foi realizada a bordo do navio oceanográfico "Almirante Cấmara", da Diretoria de Hidrografia e Navegação do Ministério da Marinha, no período de 16 a 23 de julho de 1979 , durante a primeira fase da Operação Geocosta Rionl.

METODOLOGIA Foram realizadas seis estações oceanográficas, sendo três em frente à praia de Itaipuaçu e três em frente à praia de Guaratiba (Fig. 1). A duração das observações foi de 6 horas para as estaçðes próximas à praia e de 11 a 25 horas para as estaçðes mais profundas.

Topografia do Fundo Para avaliação da topografia do fundo foram realizados alguns perfis, empregando simultaneamente o sonar de varredura lateral (side-scan sonar) e o ecobatímetro.

Meteorologia Medições de velocidade e direção do vento à altura de $10 \mathrm{~m}$ acima do nível do mar foram realizadas de hora em hora. Para este fim, foi instalado, em mastro fixado na proa do navio, um anemômetro e catavento marca Hobeco. $O$ catavento acusou direçð̄es freqüentemente erradas, o que decorre provavelmente do jogo do navio. Em decorrência desse fato, passou-se a utilizar os dados de direção do vento medido pelo catavento do navio. Nas operações próximas à praia, o mesmo equipamento foi instalado em terra, apresentando funcionamento normal.

Para a análise do tempo, foram utilizadas cartas sinóticas publicadas pela Diretoria de Hidrografia e Navegação do Ministério da Marinha.

Medição de Ondas Estimativas da direção, da altura e do período das ondas foram realizadas a cada hora. A determinação do período foi feita medindo com um cronômetro o tempo da passagem de 21 cristas por um ponto fixo e dividindo o resultado por 20. A direção foi medida com bússola. A altura das ondas foi determinada a meia-nau, empregando como peso uma placa de ferro presa a uma corda e medindo no casco, com o navio em posição estável, a diferença de altura entre a altura média do vale e da crista de uma sucessão de ondas.

Correntometria Foram utilizados dois correntômetros, um Bendix com rotor Savonius e, nas estaçðes próximas à praia, outro Hidrocean de características similares ao primeiro, porém alimentado por pilhas. Nestas últimas, devido à proximidade da costa, foi empregado um barco inflável.

As mediçðes foram realizadas de hora em hora à superfície, meia-água e próximo ao fundo, com leituras sucessivas de 10 min de duração.
Coleta de Sedimentos As amostras dos sedimentos de fundo foram coletadas de hora em hora em cada estação, empregando amostradores de mandíbula tipo Van Veen e Shipeck.

Fixação da velocidade crítica de transporte - As velocidades críticas de erosão foram fixadas em função da granulometria e do peso específico $\left(2,65 \mathrm{~g} . \mathrm{cm}^{-3}\right)$ dos sedimentos para velocidades medidas a $100 \mathrm{~cm}$ do fundo $\left(U_{100}\right)$ (Fig. 2).

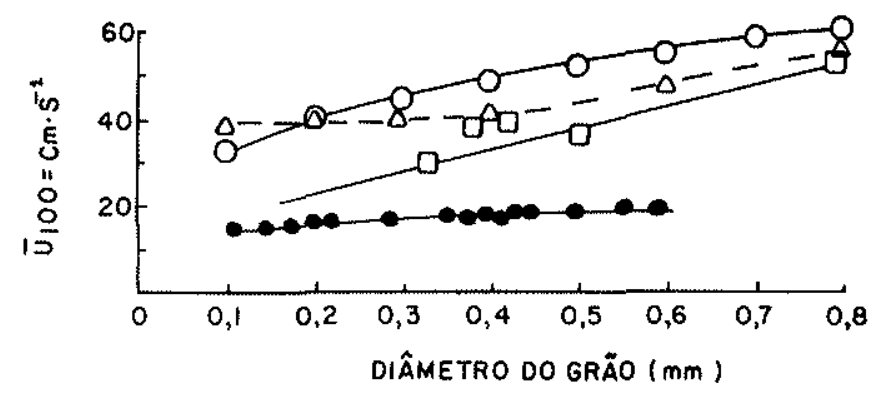

Figura 2 - Velocidades críticas de $\left(\bar{U}_{100}\right)$ para vários diametros de grãos com densidade de 2,65 g. $\mathrm{cm}^{-3}$, segundo Sundborg, 1956 ( $\Delta$ ); Sternberg, 1971 ( $\square$ ); Sundborg, modificado por Miller et al., 1977 (O); $e$ Gadd et al., 1978 (O)

A impossibilidade de realizar as medidas a $100 \mathrm{~cm}$ do fundo tornou necessária a transformação de $U_{100}$ para outros níveis um pouco mais afastados do fundo, porém ainda dentro da camada-limite (boundary layer), empregando a equação de Karman-Prandtl (Sundborg, 1956, p. 166):

$$
U_{z}=5,75 U_{*} \log _{10}\left(\frac{30,2 \cdot Z}{\alpha \cdot k_{s}}\right)
$$

em que $U_{z}=$ Velocidade da corrente a uma distância $z$ do fundo

$U_{*}=$ Velocidade de cisalhamento (shear stress velocity)

$$
U_{*}=\frac{U_{z}}{5,75 \log _{10}\left(\frac{30,2 \cdot Z)}{\alpha \cdot k_{s}}\right)}
$$

$k_{s}=$ Altura das irregularidades do fundo. Corresponde, no caso de fundos arenosos lisos, ao diâmetro dos sedimentos, ou melhor, ao $25 \%$ percentil de uma distribuição granulométrica acumulada, de modo que $75 \%$ da distribuição é de material mais fino.

$\alpha=$ Fator de correção calculável em função de $U_{*}, k_{s}$ è $v$ (ver o gráfico da funçäo em Sundborg, 1956, p. 147; ou Swift, 1976, p. 96).

$\nu=$ Viscosidade cinemática. Para temperatura da água de $20^{\circ} \mathrm{C}$, salinidade de $34 \%$, $v=0,011 \mathrm{~g} \cdot \mathrm{cm}^{-1} \cdot \mathrm{s}^{-1}$.

Determinação da profundidade máxima de açăo efetiva das ondas na mobilizaçáo dos sedimentos A profundidade máxima $(h)$ da ação das ondas para mobili- 
zação dos sedimentos com diâmetro inferior a $0,05 \mathrm{~cm}$ foi determinada usando-se a equação

$$
h=\frac{L}{2 \pi} \quad \operatorname{arcsen} h\left(\frac{\pi \cdot H}{T \cdot U_{m}}\right)
$$

em que

$$
L=\frac{g}{2 \pi} T^{2} \operatorname{tg} h\left(\frac{2 \pi d}{L}\right)
$$

$$
U_{m}=\left[0,21\left(\rho_{s}-\rho\right) \frac{g}{\rho \pi^{1 / 2}}\right]^{\frac{1}{1.5}} D^{\frac{1}{3}} T^{\frac{1}{3}}
$$

em que

$$
\begin{aligned}
& L=\text { comprimento da onda } \\
& L_{0}=\text { comprimento da onda não afetada pe- } \\
& H=\text { lo fundo } \\
& T=\text { altura da onda } \\
& U_{m}=\text { velociodo da onda } \\
& d=\text { profundidade orbital crítica } \\
& \rho=\text { densidade da água } \\
& \rho_{s}=\text { peso específico do sedimento } \\
& D=\text { diâmetro dos grãos } \\
& g=\text { aceleração da gravidade }
\end{aligned}
$$

O cálculo do comprimento da onda apresenta um problema pois $L$ aparece nos dois lados da equação. Algumas simplificaçðes felizmente permitem contornar a dificuldade. Assim, para ondas não afetadas pelo fundo, ou seja,

$$
\frac{d}{L_{0}}>0,25
$$

tem-se que

$$
\operatorname{tg} h\left(\frac{2 \pi d}{L}\right) \simeq 1
$$

de modo que

$$
L_{0}=\frac{g T^{2}}{2 \pi}
$$

Para águas rasas, em que $\frac{d}{L_{0}}<0,05$,

$$
\begin{gathered}
\operatorname{tg} h\left(\frac{2 \pi d}{L}\right) \simeq \frac{2 \pi d}{L} \\
L=T \sqrt{g d}
\end{gathered}
$$

Para águas de profundidade intermediária, em que $0,25>\frac{d}{L_{0}}>0,05$, a solução é encontrada empregando tabelas preparadas por Wiegel (1954 e 1964). $O$ assunto é discutido mais detalhadamente por Komar (1976, pp. 39-47).

Em termos práticos, seria muito trabalhoso calcular a profundidade máxima de ação das ondas sem o emprego de um computador. Por isso, baseado nas equaçðes acima, foi desenvolvido por Komar e Miller (1975) um programa em linguagem Fortran que fornece as profundidades máximas de ação das ondas para sedimentos de qualquer dimensão.

\section{Cálculo de transporte dos sedimentos de fundo} transporte de sedimentos foi determinado com base na velocidade da corrente de fundo e nas características dos sedimentos, empregando a expressão

$$
q=\beta\left(U-U_{T H}\right)^{3}
$$

apresentada por Gadd et al. (1978) e obtida a partir da equação de Bagnold

$$
q=\frac{\rho_{s}}{\left(\rho_{s}-\rho\right) g} K w
$$

em que $q$ é a massa de sedimentos transportados por unidade de largura; $U$ e $U_{T H}$ são as velocidades da corrente de fundo e crítica; $\beta$ é um coeficiente de proporcionalidade; $K$ é um coeficiente determinado experimentalmente e que expressa a eficiencia com que um dado fluxo transporta sedimentos; e $w$ é a força por unidade de área transmitida ao fundo pelo fluxo do fluido.

RESULTADOS Topografia A análise dos perfis topográficos e de sonar de varredura lateral indica tratarse, em profundidade superior a $35 \mathrm{~m}$, de um fundo liso, de topografia monótona. Desta forma, a rugosidade da interface água-sedimento é essencialmente função da granulometria dos sedimentos. Nas estaçð̃es muito próximas à praia, não percorridas pelo sonar, o fundo apresenta marcas de ondulação, já que tais feiçóes foram observadas por meio de mergulho, à profundidade de $8 \mathrm{~m}$.

Meteorologia A situação meteorológica durante as medições realizadas, com exceção da Estação Charlie de Itaipuaçu, foi de tempo bom, conforme pode ser observado na sequuência de cartas sinóticas da Diretoria de Hidrografia e Navegação do Ministério da Marinha e apresentadás na Fig. 3.

A Estação Charlie de Itaipuaçu, que constitui exceção, esteve sob a influência de um ciclone extratropical com ventos de $\mathrm{NE}-\mathrm{SE}$ e velocidades de 10 a 15 nós.

Medição de Ondas A profundidade máxima de açăo das ondas, isto é, à qual a velocidade orbital ainda mobiliza os sedimentos, nunca ultrapassou os $30 \mathrm{~m}$ em todas as estaçōes analisadas, situando-se com mais frequência nos limites de $20 \mathrm{~m}$. Desta forma, a ação çonjugada de ondas e correntes passa a desempenhar um papel importante no transporte de sedimentos a partir da curva batimétrica de $20 \mathrm{~m}$ em direção à praia.

Nas estaçðes Bravo e Charlie de Itaipuaçu e Guaratiba, não ocorreu mobilização dos sedimentos, por efeito isolado das ondas, já que as profundidades eram superiores às da ação máxima das mesmas. Nas estaçðes Alfa de Itaipuaçu e Guaratiba, com profundidade da ordem de $15 \mathrm{~m}$, o estado do mar, durante as mediçð̃es, foi tão calmo que também ali a ação das ondas, durante as observaçðes, foi desprezível. Entretanto, pelo exposto acima, as velocidades orbitais das ondas, nessa profundidade, frequentemente ultrapassam o valor crítico.

Correntometria A geração de um sistema de correntes induzido pelo vento cria inicialmente, junto à costa, um sistema de correntes de deriva segundo o modelo de Ekman. Após algum tempo, desde que o vento não mude de direção, estabelece-se um declive que por sua vez induz ao desenvolvimento de um sistema de correntes de declive. A superposição dos dois sistemas (deriva mais declive) dá, como resultante, origem ao sistema de correntes litorais (Silva, 1964 e 1968). 


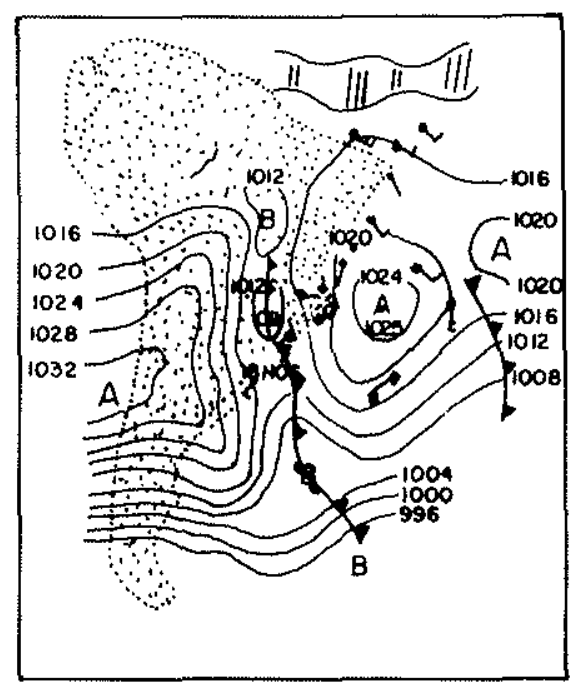

a) $19 / 07 / 1979$

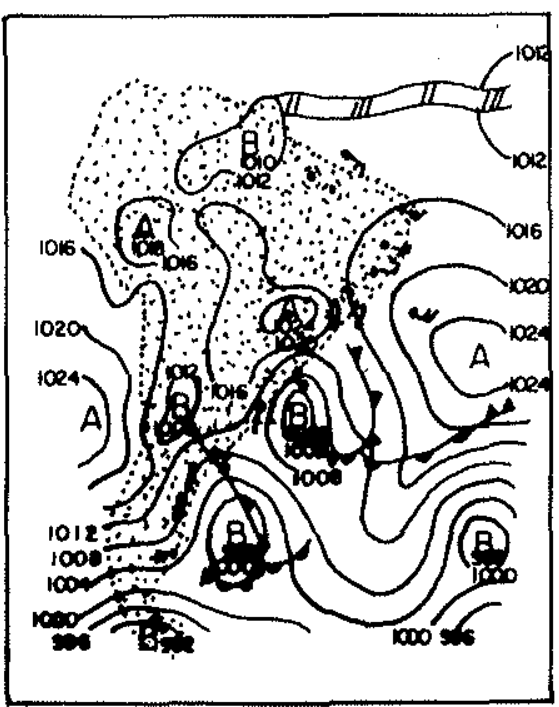

c) $21 / 07 / 1979$

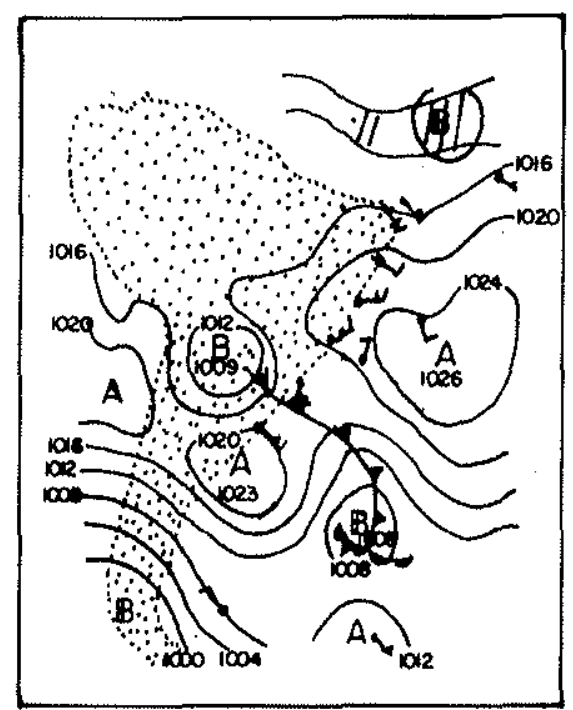

e) $03 / 08 / 1979$

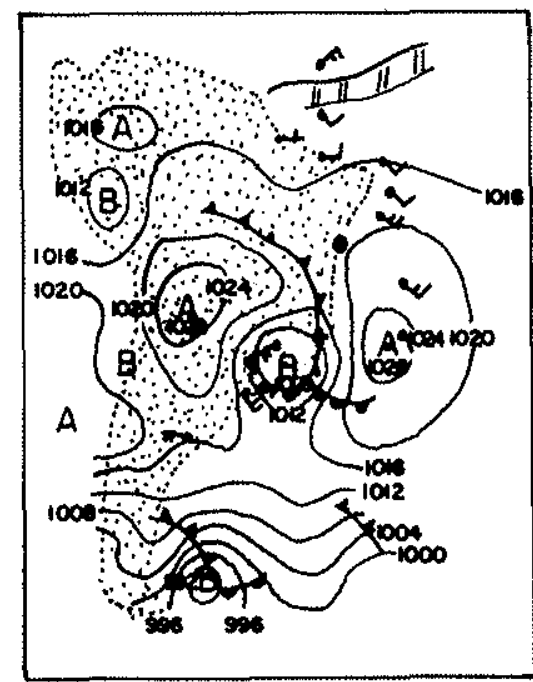

b) $20 / 07 / 1979$

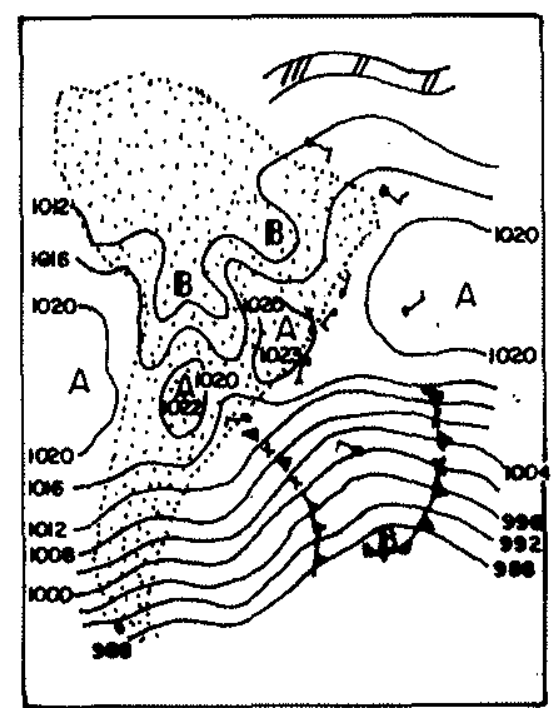

d) $22 / 07 / 1979$

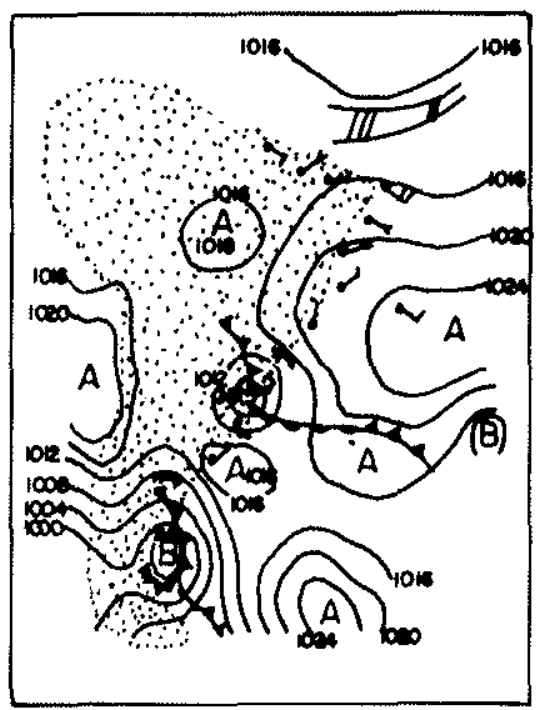

f $104 / 08 / 1979$

Figura 3 - Situação meteorológica vigente durante a realização das estaçôes oceanográficas 
Tabela 1 - Velocidade das correntes de fundo provocadas por um vento soprando paralelamente à costa

\begin{tabular}{c|l|l|l}
\hline \multirow{2}{*}{$\begin{array}{c}\text { Profund. } \\
\mathrm{da} \\
\text { agua (m) }\end{array}$} & \multicolumn{3}{|c}{ Velocidade do vento (nó) } \\
\cline { 2 - 4 } & 30 & 15 & 10 \\
\hline \multirow{2}{*}{45} & $\begin{array}{l}h / D=0,3 \\
U_{0,9}=4,1 \mathrm{~cm} \cdot \mathrm{s}^{-1}\end{array}$ & $\begin{array}{l}h / D=0,7 \\
U_{0,9}=7,2 \mathrm{~cm} \cdot \mathrm{s}^{-1}\end{array}$ & $\begin{array}{l}h / D=1,0 \\
U_{0,9}=8,2 \mathrm{~cm} \cdot \mathrm{s}^{-1}\end{array}$ \\
\hline \multirow{2}{*}{40} & $\begin{array}{l}h / D=0,3 \\
U_{0,9}=4,1 \mathrm{~cm} \cdot \mathrm{s}^{-1}\end{array}$ & $\begin{array}{l}h / D=0,6 \\
U_{0,9}=6,7 \mathrm{~cm} \cdot \mathrm{s}^{-1}\end{array}$ & $\begin{array}{l}h / D=1,0 \\
U_{0,9}=8,2 \mathrm{~cm} \cdot \mathrm{s}^{-1}\end{array}$ \\
\hline \multirow{2}{*}{30} & $h / D=0,2$ & $\begin{array}{l}h / D=0,45 \\
U_{0,9}=4,6 \mathrm{~cm} \cdot \mathrm{s}^{-1}\end{array}$ & $\begin{array}{l}h / D=0,7 \\
U_{0,9}=5,1 \mathrm{~cm} \cdot \mathrm{s}^{-1}\end{array}$ \\
\hline \multirow{2}{*}{15} & $\begin{array}{l}h / D=0,1 \\
U_{0,9}=4,1 \mathrm{~cm} \cdot \mathrm{s}^{-1}\end{array}$ & $\begin{array}{l}h / D=0,2 \\
U_{0,9}=2,0 \mathrm{~cm} \cdot \mathrm{s}^{-1}\end{array}$ & $\begin{array}{l}h / D=0,3 \\
U_{0,9}=1,5 \mathrm{~cm} \cdot \mathrm{s}^{-1}\end{array}$ \\
\hline
\end{tabular}

No sistema de deriva puro, a velocidade da corrente próxima ao fundo é apenas da ordem de $10 \%$ ou menos da velocidade da corrente superficial, ao passo que no sistema de correntes litorais essa velocidade pode chegar a $50 \%$. Tais velocidades máximas são atingidas com ventos soprando paralelamente à costa, decrescendo à medida que o ângulo de incidência do vento em relação à costa se aproxima de $90^{\circ}$ ou $270^{\circ}$ e que a topografia interfere no desenvolvimento do sistema de correntes, ou seja, à medida que decresce a relação entre a profundidade da água (h) e a espessura da camada friccional de Ekman $(D)$. É interessante verificar, baseado nos hodógrafos publicados em forma de tabelas por Silva (1968), que na plataforma continental interna o aumento de velocidade da corrente, que se poderia esperar com o aumento da velocidade do vento, é anulado pelo efeito exercido pelo fundo, como bem demonstra a Tab. 1 , a ponto de um vento de 10 nós provocar um fluxo mais rápido que um vento de 30. A mesma tabela ainda mostra claramente que em profundidades inferiores a $30 \mathrm{~m}$ as correntes de fundo geradas pelo vento são praticamente despreziveis.

Para a área em questão, com a linha de costa orientada de leste para oeste, apenas correntes litorais induzidas por ventos dos octantes NE, E e SE (tempo bom) ou NW, W e SW (frente fria) podem, em profundidades superiores a $30 \mathrm{~m}$, apresentar fluxos que associados a correntes induzidas por ondas, por variaçðes de densidade ou pela maré, contribuir para ultrapassar a velocidade crítica de erosão. Nessas condições, o fluxo será orientado para a costa, quando sob domínio do ciclo de tempo bom, e para o alto-mar, quando sob domínio de frente fria. Em profundidades inferiores a $30 \mathrm{~m}$, o efeito das ondas sobre o fundo passa gradativamente a desempenhar um papel mais importante à medida que decresce a profundidade, o mesmo ocorrendo sob condições de tempestade. Um outro aspecto a ser levado em conta é até que velocidade de vento a circulação obedece ao modelo de Ekman. Swift (1976), citando o trabalho de Assaf et al. (1971), admite que ventos com velocidade superior a 5 nós provocariam a transição entre circulação de Ekman para a de Langmuir, caracterizada por faixas paralelas com alternância de subsidência e ressurgência que se desenvolvem ao longo de vórtices helicoidais horizontais. Entretanto, Assaf et al., no mesmo artigo, mostram que em águas rasas (profundidade $50 \mathrm{~m}$ ) o sistema de Ekman ain- da foi observado com ventos de 12 nós, quando então ambos os sistemas ocorrem simultaneamente. Em termos práticos, no que tange à avaliação da direção e da intensidade da corrente de fundo na plataforma continental interna, a adoção d'o modelo de Ekman e suas conseqüências em termos de declive parecem assim adequadas.

A análise das características do vento, baseada em cinco anos de observações realizadas na Ilha Rasa pela Diretoria de Hidrografia e Navegação do Ministério da Marinha, mostra que os ventos dominantes são os dos octantes N, NE, E e SW (Fig. 4a), ocorrendo as maiores intensidades médias sob ventos de $\mathrm{E}, \mathrm{SW}$ e W (Fig. $4 b$ ) e que $50 \%$ dos ventos registrados apresentam velocidade inferior a 8 nós; $80 \%$, inferior a 15 nós; e $95 \%$, inferior a 22 nós (Fig. 4c). Assim, considerando principalmente a freqüência, são os ventos de NE e E (tempo bom) e SW (frente fria) que passam a apresentar importância sob o ponto de vista de geração de correntes de fundo. Desse modo, o balanço dos fluxos induzidos pelo vento deverá ser nitidamente em direção a noroeste decorrentes da ação dos ventos $\mathrm{N}$ e $\mathrm{E}$, e secundariamente em direção a SE por ação do vento SW. Que tais fluxos são insuficientes para erodir os sedimentos já foi discutido acima. Entretanto, associados a ondas e a correntes de maré ou de densidade poderão ocasionalmente gerar uma resultante com velocidade suficiente ao transporte de sedimentos.

No caso da maré, devido a seu caráter rotativo, ocorrerá intermitentemente uma superposição entre a direção da corrente gerada pelo vento e da corrente de maré.

Resumindo, sob condiçðes de tempo bom, com vento soprando de NE ou E e ondas propagando-se de SE para $\mathrm{NW}$, deverá ocorrer fluxo em direção à costa, em que a ação das ondas sobre o fundo aumenta progressivamente com a diminuição da profundidade, principalmente a partir da isóbata de $20 \mathrm{~m}$, podendo entåo ocorrer um transporte de sedimentos em direção à costa como decorrência da soma vetorial entre corrente litoral, corrente de maré e ação das ondas. Sob condiçðes moderadas, portanto, deverá esperar-se um transporte de sedimentos de preferência para a costa: Sob condiçð̃es excepcionais, isto é, tempestades fortes, o fator preponderante deverá ser exercido pelas ondas de SW já que as correntes litorais sob ação de ventos mais fortes apresentam próximo ao fundo, devido à fricção, fluxos de pequena intensidade. Nessa situaçăo, as ondas deverão suspender os sedimen. 
tos a partir de profundidades da ordem de $40 \mathrm{~m}$, deslocando-os na direção de propagação no momento da passagem da crista e em sentido contrário, com menor intensidade e maior duração, por ocasião da passagem do vale da onda. $O$ que vai definir a resultante de transporte nesse caso é a direção do fluxo resultante das correntes unidirecionais que se vão superimpor ao fluxo induzido pelas ondas. A resultante de transporte, então, deverá situar-se entre NE e SE.

Durante $54 \%$ do tempo de observação, nas quatro estações mais afastadas da praia, ocorreu fluxo da corrente de fundo para $\mathrm{S}$ e SE, portanto em direção ao oceano aberto, $26 \%$ em direção a $\mathrm{N}$ e NE, ou seja, para a costa, e $13 \%$ em direção a $\mathrm{E}$, isto é, paralelamente à costa. É interessante registrar que praticamente não ocorreu fluxo em direção a W.

A análise das observações realizadas em todas as estações indica que mụdanças de direção do vento provocam mudanças na direção da corrente de fundo. A velocidade, tanto na corrente de superfície quanto na de fundo, foi sempre superior à esperada pela ação do vento. Quanto à direção, ocorreu fluxo orientado para a costa, de preferência sob condições de vento dos quadrantes NE, E e S, e para o alto mar sob vento dos quadrantes $N, E, S E$, SW e NW, correspondendo portanto, apenas em parte, ao modelo descrito acima. É possível que tal fato resulte do lapso de reação do sistema de correntes às mudanças de direção do vento que, por serem frequientes, impediram a adaptação desse sistema às diversas direçðes do vento.

A intensidade dos fluxos quase sempre foi insuficiente para o transporte dos sedimentos arenosos, com exceção da Estação Charlie de Itaipuaçu, onde os valores críticos de transportes foram ultrapassados durante algumas horas (Fig. 5). Tal fato aparece associado à proximidade de uma frente fria (Fig. $3 b$ ), como se descreveu no item "Meteorologia".

Durante o período de ultrapassagem do valor crítico, o vento soprava de $\mathrm{NE}$ com intensidade de 10 a 15 nós e a corrente de fundo dirigia-se para $\mathrm{N}, \mathrm{NE}$ com velocidade de 25 a $31 \mathrm{~cm} . \mathrm{s}^{-1}$, portanto condizente em termos de direção com o esperado. O cálculo da corrente de maré, a partir da corrente geral medida, mostrou que a velocidade dessa corrente na ocasião era responsável por $25 \%$ a $30 \%$ da velocidade da corrente geral e que durante o período de ultrapassagem do valor crítico a direção da corrente de maré se aproximava da direção da corrente geral. Não obstante, a componente que deveria representar a corrente litoral apresenta velocidade superior à que poderia ser gerada pelo vento atuante.

Análise dos sedimentos A análise dos sedimentos restringiumse à determinação da cor pela carta de Munsell e das características granulométricas por meio de peneiramento.

A análise granulométrica teve, por um lado, a finalidade de verificar se a variação textural, por efeito de ondas e correntes, seria de tal ordem que provocaria uma variação nos valores de tendência central da distribuição granulométrica das diferentes amostras de cada estação, a ponto de mudar sua classificação dentro da escala de
ILHA RASA 1975-1979

$\%$ a) FREQUUENCIA DOS VENTOS DOMINANTES

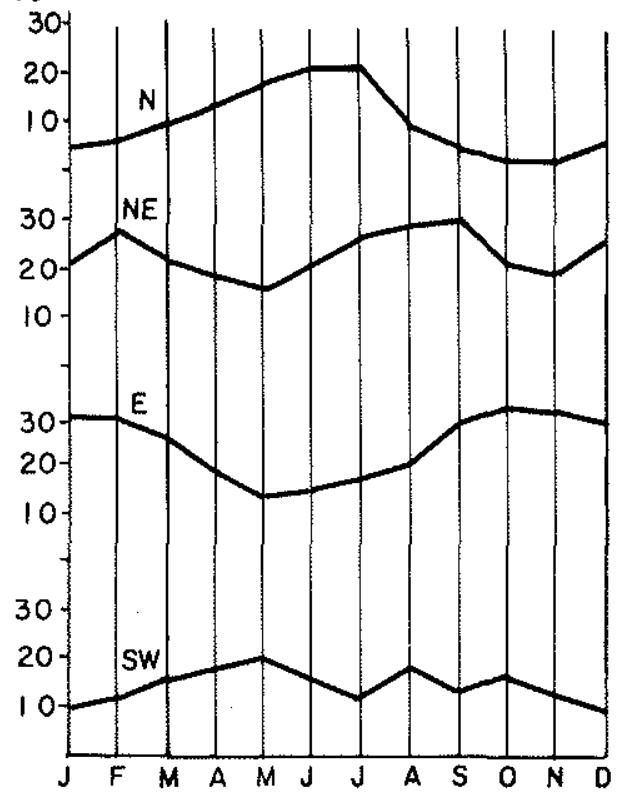

b) INTENSIDADE MÉDIA DOS VENTOS

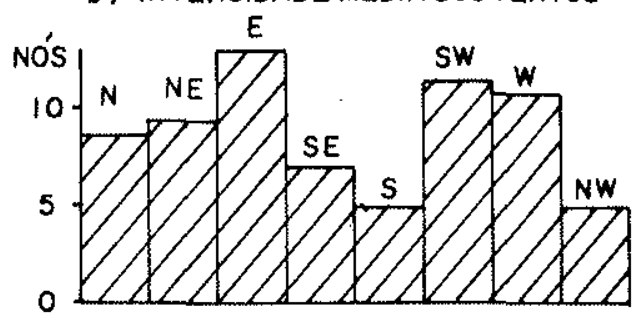

c) FREQUUENCIA DAS VELOCIDADES DOS VENTOS

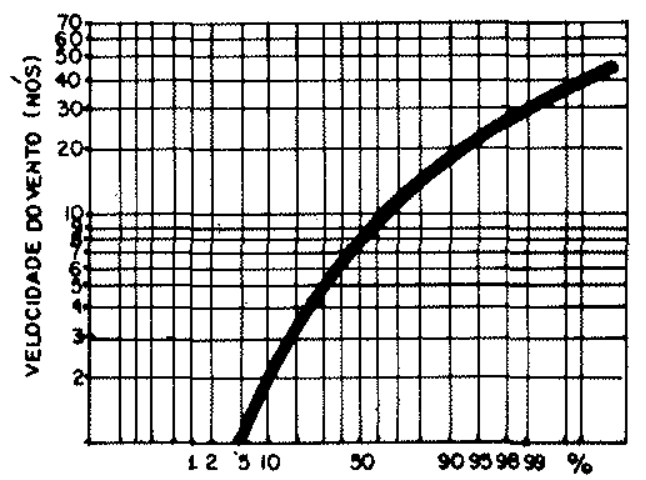

Figura 4-Estatistica dos ventos baseada em observações realizadas na Ilha Rasa

Wentworth, e, por outro lado, verificar a validade dos valores críticos de velocidade de Gadd et al. (Fig. 2).

A Fig. 6 mostra a superposição das curvas granulométricas acumuladas da Estação Charlie de Itaipuaçu, única em que a velocidade da corrente de fundo ultrapassou, durante algumas horas, o limite crítico. Os valores médio e mediano das amostras coletadas mantiveram-se sempre no intervalo de 1 a $2 \phi$ (de 0,5 a $0,25 \mathrm{~mm}$ ) indicando tratar-se de areia média, não se registrando portanto modificaçōes na classe textural. 

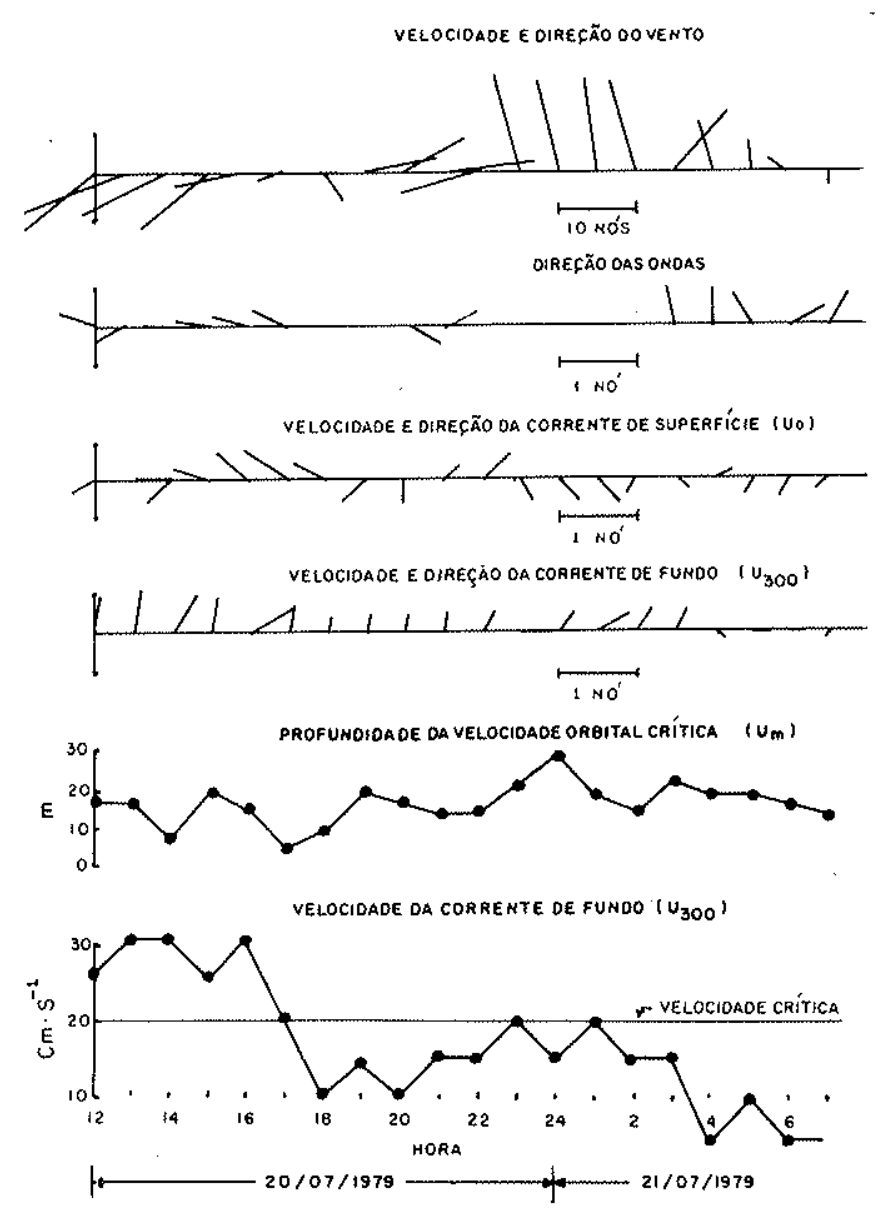

Figura 5 - Parâmetros oceanográficos da Estação Charlie de Itaipuaçu

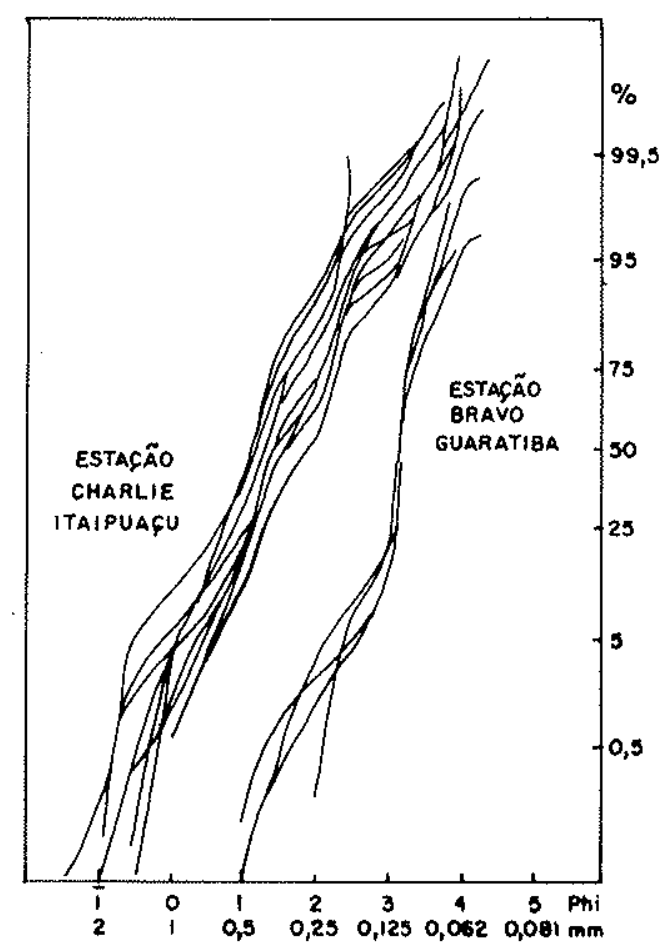

Figura 6 - Curvas granulométricas de frequência acumulada dos sedimentos na área das estaçôes Charlie de Itaipuaçu e Bravo de Guaratiba
A tentativa de avaliação da resposta textural à ação de ondas e correntes foi também restrita à Estação Charlie de Itaipuaçu pela mesma razão já exposta acima. A correlação entre os parâmetros texturais de todas as amostras com os parâmetros oceanográficos não se mostrou significativa. Isso decorre parcialmente do fato de a velocidade da corrente ter sido inferior ao valor crítico, para a mobilização dos sedimentos, durante a maior parte do tempo de observação. Uma outra razão reside no fato de o navio ter girado em torno da âncora por efeito de mu* dança de direção do vento e da corrente superficial, fazendo com que a amostragem se dispersasse numa área muito ampla, e ainda pela inadequação do equipamento de amostragem que tende a penetrar no sedimento mais que o desejado, coletando estratos depositados sob diferentes condições hidrodinâmicas.

É surpreendente que, apesar dessas restrições, tenha ocorrido com relação significativa entre uma variável oceanográfica e outra textural quandó restrita ao período durante o qual a velocidade da corrente de fundo ultrapassou o limite crítico. Assim, a análise da Fig. 7 indica que a dimensão média dos sedimentos acompanha a curva de variação da profundidade da velocidade orbital crítica, aumentando de tamanho com o aumento dessa profundidade $(r=0,86 ; P=97,4 \%)$. É como se a oscilação da onda provocasse um impulso adicional capaz de mobilizar principalmente as fraçбes mais finas dos sedimentos.
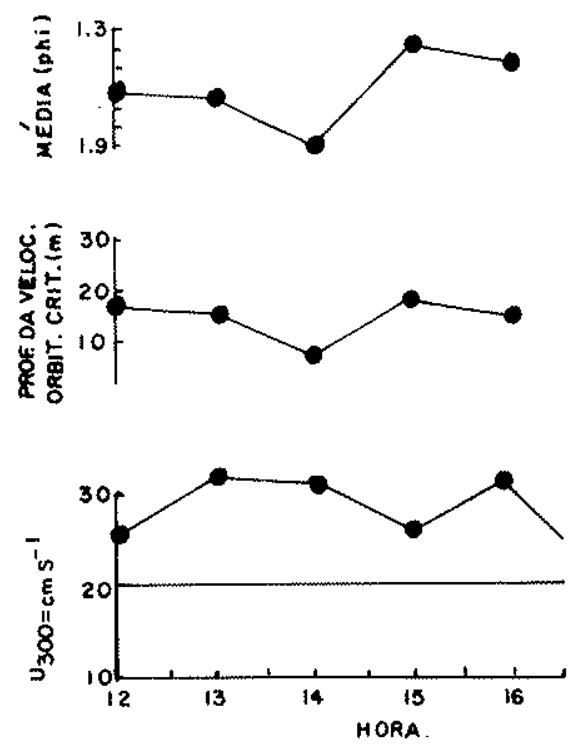

Figura 7 - Correlação entre parâmetros oceanográficos e texturais durante o período ae ultrapassagem de velocidade crítica de transporte de sedimentos na Estação Charlie de Itaipuaçu

Sundborg (1956), ao analisar a resposta textural de sedimentos à ação de uma corrente, afirma que para dimensões entre 0,3 e $0,1 \mathrm{~mm}$ o fluxo é turbulento ou transicional. A turbulência não se estende completamente aos interstícios entre as partículas, de modo que grãos mais abrigados deixam de ser afetados. Por outro lado, os grãos mais expostos, de maior diâmetro, sofrem a ação de um esforço maior. Conseqüentemente, na fase inicial do processo erosivo, as fraçðes mais grosseiras seriam as mais facilmente mobilizadas. 
Tabela 2 - Taxas de transporte da Estação Charlie de Itaipuaçu

\begin{tabular}{c|c|c|c}
\hline $\begin{array}{c}\text { Velocidade } \\
\bar{U}_{300}=\mathrm{cm} \cdot \mathrm{s}^{-1}\end{array}$ & $\begin{array}{c}\text { Indice de } \\
\text { transporte } \\
\left(\bar{U}_{300}-U_{T H}\right)^{3}\end{array}$ & $\begin{array}{c}\text { Taxa de } \\
\text { transporte }(q) \\
\left(\mathrm{g} \cdot \mathrm{cm}^{-1} \cdot \mathrm{s}^{-1}\right)\end{array}$ & $\begin{array}{c}\text { Direção } \\
\left({ }^{\circ}\right)\end{array}$ \\
\hline 25,7 & 185 & $3,2 \times 10^{-3}$ & $7^{\circ}$ \\
30,9 & 1295 & $2,2 \times 10^{-2}$ & $8^{\circ}$ \\
30,9 & 1295 & $2,2 \times 10^{-2}$ & $33^{\circ}$ \\
25,7 & 185 & $3,2 \times 10^{-3}$ & $8^{\circ}$ \\
30,9 & 185 & $3,2 \times 10^{-3}$ & $64^{\circ}$ \\
\hline \multicolumn{2}{r}{} & $21^{\circ}$ & $25,15 \times 10^{-2}$ \\
\hline
\end{tabular}

Essas observações, entretanto, aplicam-se a condiçð̌es de erosão por ação de correntes unidirecionais típicas de processos fluviais. Suspeitamos de que, em condiçðes de velocidades subcríticas, a ação conjugada de ondas e correntes, típica de ambiente de plataforma continental, talvez imprima um comportamento diferente, fazendo com que as frações mais leves, portanto de menor diâmetro, sejam suspensas por ação da onda e transportadas por ação de correntes unidirecionais, deixando atrás de si um depósito residual mais grosseiro (Muehe, D. e Döbereiner, C., 1977, e Muehe, D., 1979). Na prática, essa constatação é dificultada, pois a eliminação de parte da fração granulométrica do local de amostragem pode ser compensada pela concomitante introdução de sedimentos da mesma faixa granulométrica.

A interpretação dos parâmetros texturais dessas amostras não chegou portanto a oferecer respostas conclusivas sobre a mobilização dos sedimentos, mas forneceu para a estação de Itaipuaçu dados que parecem apoiar essa possibilidade.

Uma indicação adicional, da possível mobilização dos sedimentos, representa a mudança de cor dos mesmos que de cinza-oliva (5Y 4/2) passou a marrom-oliva $(2,5 Y$ 4/4) para, com a diminuição da velocidade da corrente e redeposição das partículas da fração silte-argila, voltar ao oliva $(5$ Y $4 / 3)$.

Em suma, com base na análise preliminar dos dados, há indícios de que o material foi pelo menos parcialmente mobilizado, não rejeitando assim o limite crítico adotado por Gadd et al. (1978).

Transporte de sedimentos Durante o período de observação, o transporte de sedimentos de fundo foi extremamente reduzido, limitando-se a algumas horas durante a realização da Estação Charlie de Itaipuaçu (Fig. 5).

A resultante de transporte (Tab. 2) apresentou uma taxa relativamente elevada de $5,15 \times 10^{-2} \mathrm{~g} \cdot \mathrm{cm}^{-1} \cdot \mathrm{s}^{-1}$ com direção para $21^{\circ}$ (NNE). O curto espaço de tempo em que ocorreu mobilização, porém, faz com que essa taxa se torne pouco representativa, correspondendo, se todo o material fosse acumulado na praia, a um acréscimo em seu perfil de apenas $0,77 \mathrm{~m}^{2}$ o que, para a praia de Itaipuaçu, representa cerca de $5 \%$ da variação diária de sua seção transversal.

CONCLUSÃo O transporte de sedimentos na plataforma continental próxima à costa, e com profundidades entre 30 e $45 \mathrm{~m}$, parece ser em geral muito reduzido, ocor- rendo em períodos de curta duração por ação conjugada de correntes litorais, correntes de maré e ondas.

Em função do regime de ventos, há indícios de que ocorre ocasionalmente transporte em direção à costa sob condições de tempo bom com vento $\mathrm{NE}$ ou $\mathrm{E}$ e em direção paralela à costa ou para o alto-mar sob condições de frente fria com vento de SW.

$\mathrm{O}$ afluxo de sedimentos de outras áreas da plataforma continental para dentro do subsistema ItaipuaçuGuaratiba será possivelmente muito reduzido quando não ausente. $O$ caráter não-progradacional da linha de costa atual inferido pelo padrão de distribuição dos sedimentos na antepraia parece confirmar essa suposição.

Apesar da menor freqüência de ocorrência de ventos de SW, associados à entrada de frentes frias em relação aos ventos de tempo bom, e apesar de sua menor velocidade média quando comparado com esses mesmos ventos, suas velocidades máximas são maiores sendo também maiores as ondas geradas nessas ocasibes. Portanto, os efeitos em termos de transporte deverão ser mais significativos, devendo ocorrer algum transporte grosso modo em direção a leste. A ocorrência de sedimentos sensivelmente mais finos na plataforma continental interna de Guaratiba (Fig. 6) pelo menos não invalida essa hipótese, mas pode também ter outras explicaçôes.

Em vista do reduzido período de observação e da forma ainda inadequada em que os dados tiveram que ser coletados, esperamos que as presentes conclusões sejam consideradas mais como hipóteses de trabalho e não como modelo representativo do transporte de sedimentos. Esperamos que o mapeamento detalhado da distribuição dos sedimentos de toda a área, em fase de conclusão, e o lançamento de correntógrafos para registros de longa duração possam trazer maiores subsídios à compreensão do regime de mobilização de sedimentos na plataforma continental interna da região.

Agradecimentos Queremos expressar nossos agradecimentos aos comandantes Hugo Bernardi Júnior, Chefe do Departamento de Geofísica, e Luiz Carlos Ferreira da Silva, Encarregado da Divisão de Prospecção Geofísica da Diretoria de Hidrografia e Navegação do Ministério da Marinha, pelo decisivo apoio para a execução do projeto, ao capitão-de-fragata Antônio Carlos de Oliveira e Silva, comandante do navio oceanográfico "Almirante Câmara", e demais oficiais e guarnição desse navio pela cooperação e dedicação demonstradas durante a realização dos trabalhos, e aos estudantes de Geografia, Al- 
cebíades de Souza Teixeira Filho e Marcos Antônio Santos, e de Meteorologia, Cristina Baldissara Fernandes e Watson Gomes da Silva, pela valiosa participação na coleta de dados a bordo. Ao geólogo Renato O. Kows- mann, do Centro de Pesquisas da Petrobrás, agradecemos a revisão crítica do manuscrito. Recursos financeiros para a realização do trabalho foram concedidos pelo CNPq e CEPG/UFRJ.

\section{BIBLIOGRAFIA}

ASSAF, G., GERARD, R, e GORDON, A.L. - 1971 - Some mechanism of oceanic mixing revealed in aerial photographs. Journ. Geophys. Res., 76, 27, $6550-6572$.

GADD, P.E., LAVELLE, J.W. e SWIFT, D.J.P. - 1978 - Estimates of sand transport on the New York shelf using near-bottom current meter observations. Journ. Sed. Petrology 48, 1, 239-252.

KOMAR, P.D. e MILLER, M.C. - 1973 - The threshold of sediment movement under oscillatory water waves. Journ. Sed. Petrology 43, 1101-1110.

KOMAR, P.D. e MLLLER, M.C. - 1975 - On the comparison between the threshold of sediment motion under waves and unidirectional currents with a discussion of the practical evaluation of the threshold. Journ. Sed. Petrology 45, 1, 362-367.

KOMAR, P.D. - 1976 - Beach Processes and Sedimentation. Prentice-Hall, Englewood Cliffs, N.J., 429 pp.

LANGMUIR, I. - 1938 - Surface motion of water induced by wind. Science /87, $2250,119-123$

MILLER, MAC., MCCAVE, I.N. e KOMAR, P.D. - 1977 - Threshold of sediment motion under unidirectional currents. Sedimentology 24, 507-527.

MUEHE, D. - 1979 - Sedimentology and topography of a high energy coastal environment between Rio de Janeiro and Cabo Frio, Brazil. An. Acad. Bras. Ciênc. 51, 3 .

MUEHE, D. e DÖBEREINER, C. - 1977 - Dinâmica do fundo marinho ao longo do pier de Ipanema, Rio de Janeiro. An. Acad. Bras. Ciênc. 49, 2.
MUEHE, D. - 1979 - Relatório de Bordo da Operação Geomar X Diretoria de Hidrografia e Navegação, Ministério da Marinha.

SILVA, P.M. da - 1964 - Solução oceanográfica de um problema de eliminação de esgoto sanitário. IX Congresso Interamericano de Engenharia Sanitária. Bogotá, Colômbia.

SILVA, P.M. da - $1968-$ Correntes litorais produzidas pelo vento. Instituto de Pesquisas da Marinha, Publ. 20.

STERNBERG, R.W. - 1971 - Measurement of incipient motion of sediment particles in the marine environment. Marine Geol. 10, 2, 113-119.

SUNDBORG, A. -1956 - The river Klaräven, a study of fluvial processes, Geogra fiska Annaler 38, 2

SWIFT, D.J.P. - 1976 - Coastal Sedimentation. Marine Sediment Transpor: and Environmental Management. Edit. Stanjey, D.J. and Swift, D.J.P. John Wiley Sons.

WIEGEL, R.L. - 1954 - Gravity Wave Tables of Functions. Council on Wave Research, Engineering Foundation, Univ. of California, Berkeley.

WIEGEL, R.L. - 1964 - Oceanographical Engineering. Prentice-Hall, Englewood Cliffs, N.Y., $532 \mathrm{pp}$

ZENKOVICH, V.P. - 1976 - Preserving the nature of seashores. Geoforum 7, 395-397.

Recebido em 25 de novembro de 1980 